\title{
Charge Transport Model for Photovoltaic Devices based on Printed Polymer:Fullerene Nanoparticles
}

Natasha A. D. Yamamoto ${ }^{1,2}$, Margaret E. Payne ${ }^{1}$, Marlus Koehler ${ }^{2}$, Antonio Facchetti ${ }^{3}$, Lucimara S. Roman ${ }^{2}$, and Ana C. Arias ${ }^{1} *$

${ }^{1}$ Department of Electrical Engineering and Computer Science, University of California, Berkeley, CA 94720, United States of America

${ }^{2}$ Department of Physics, Federal University of Paraná, CP 19044, CEP 81531-980, Curitiba, PR, Brazil

${ }^{3}$ Polyera Corporation, Skokie, IL 60077, United States of America

Corresponding author: acarias@eecs.berkeley.edu

Keywords: Electrical transport model, polymer nanoparticle, aqueous dispersion, flexible solar cells, doctor blade coating.

\begin{abstract}
The electrical transport properties of aqueous semiconducting nanoparticle films are fully described by a phenomenological model that relates intrinsic film morphology to photovoltaic response. The model is applied to a new bulk heterojunction blend, composed of organic semiconducting nanoparticles formed from the polymer donor poly[ $\{2,6-(4,8-$ didodecylbenzo[1,2-b:4,5-b']dithiophene) $\}$-alt-\{5,5-(2,5-bis(2-butyloctyl)-3,6-dithiophen-2yl- 2,5dihydropyrrolo[3,4-c] 57pyrrole-1,4-dione)\}] (P(TBT-DPP)) and the fullerene indene-
\end{abstract}


$\mathrm{C}_{60}$-bisadduct (ICBA) synthesized by the miniemulsion method. The nanoparticle inks are printed from an aqueous dispersion onto flexible ITO-free substrates yielding power conversion efficiency of $2.6 \%$.

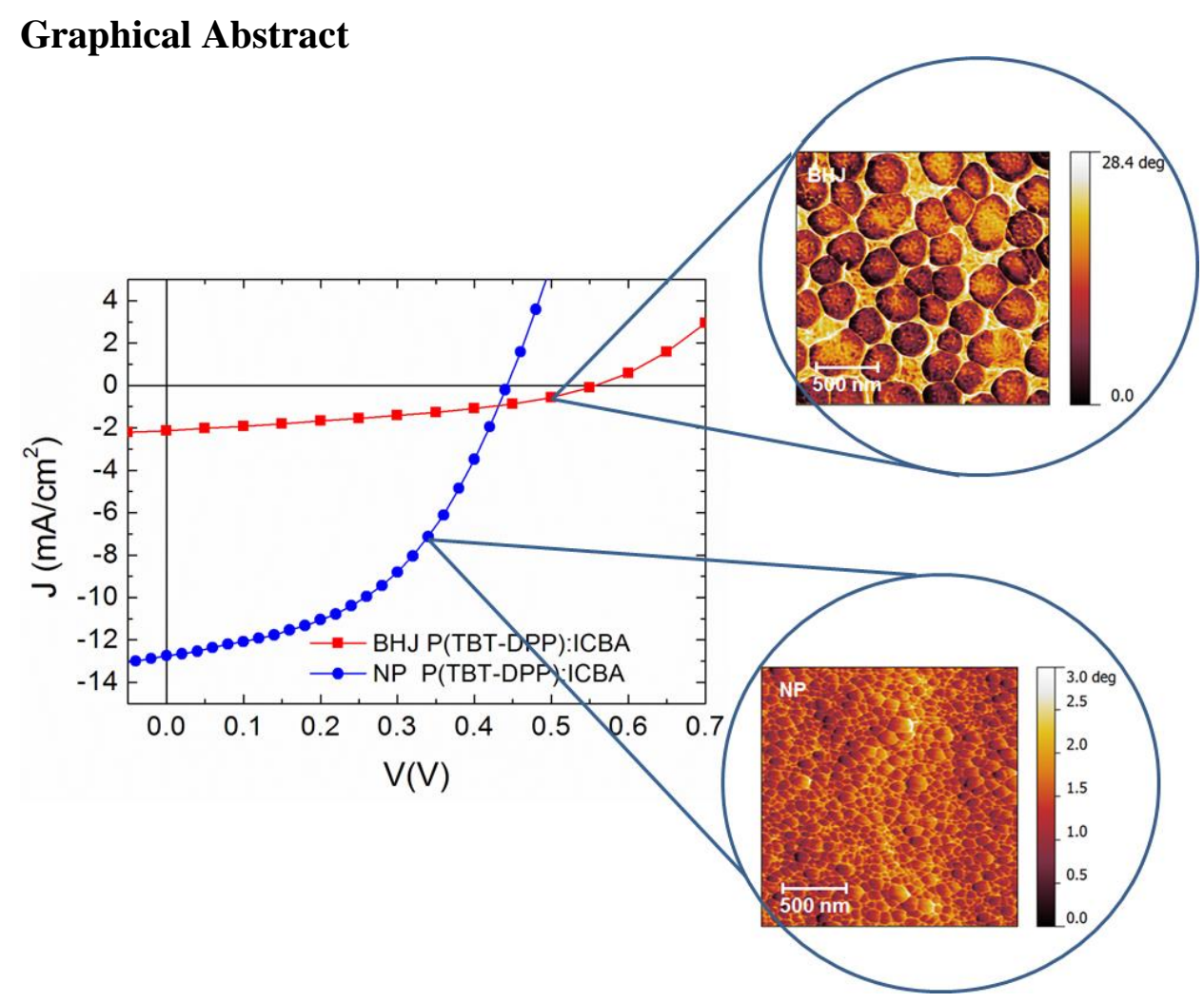

\section{Introduction}

Solar cells based on organic semiconductors have attracted significant interest due to their potential for large area production, lightweight and new form factors [1,2]. These devices are often fabricated using printing [3-8] and coating techniques that are compatible with flexible 
substrates enabling progress towards low-cost high speed production methods [9-11]. The optimization of bulk heterojunction solar cells based on polymer:fullerene blends lead to recent reports of high performance, reaching up to $10 \%$ power conversion efficiencies (PCE) [12-14]. The high PCEs achieved with devices based on blends of electron-donating and electron-accepting materials require fine control of thin film phase separation on the nanometer scale which leads to increased number of interfaces where exciton dissociation and charge generation occurs [15]. The resulting film morphology strongly depends on several processing parameters [16] including the solubility of the materials in the solvent used [17], the interaction with the substrate surface [18] the packing of the molecules, formation of domains of different blend compositions [19] and the film deposition technique [20]. It has been established that exciton dissociation can be maximized when donor and acceptor components are intimately mixed and the length-scale of the phase separation is in the range of the exciton diffusion length $[15,21]$. As a result, over the years, many methodologies to control the blend morphology have been developed: appropriate solvent choice [22] controlling the rate of solvent evaporation [23,24], thermal annealing [25,26] melting of bilayers [27] and adding solvent additives [28]. These different procedures promote the formation of a phase separated morphology that leads to improved photovoltaic performance. However the prediction and control of the final film morphology is extremely challenging due to the interplay between mixing and drying. Most laboratories use toxic and flammable organic solvents in their fabrication process of organic solar cells. Polymer nanoparticles dispersed in water are an alternative method that addresses both morphology control and scalable on non-toxic ink deposition. The miniemulsion technique [29] retains the donor/acceptor phase segregation achieved at the synthesis step regardless of the deposition solvent evaporation time or film processing method. This technique was previously utilized for synthesis of blends of polyfluorenes [30,31] and poly(3-hexylthiophene)(P3HT): phenyl$\mathrm{C}_{61}$-butyric acid methyl ester (PCBM) nanoparticles [32] deposited by blade coating 
achieving PCEs of $0.29 \%$ [33] and 0.55\% [34]. Solar cells based on spin coated blend nanoparticles of $\mathrm{P} 3 \mathrm{HT}$ and the fullerene indene- $\mathrm{C}_{60}$-bisadduct (ICBA) resulted in power conversion efficiency of $2.50 \%$ [35]. Although several photovoltaic devices based on aqueous nanoparticle dispersions have been reported [30-32,35,36], the effects of this type of donor/acceptor phase segregation on the electrical properties remains poorly explored. We fabricated blade coated devices using conventional chloroform bulk heterojunction (BHJ) and nanoparticle dispersed in aqueous media (NP) to form the active layer of flexible solar cells. We characterized the film morphology and electrical properties and fitted the experimental dark $J$ - $V$ curves using a phenomenological electric model. The nanoparticle composition and morphology were correlated to the photovoltaic performance and we demonstrate that the charge transport in nanoparticulate devices is improved when compared to the BHJ. The photovoltaic active layer of the flexible solar cells reported here, is composed of a new nanoparticulate bulk heterojunction blend of the polymer poly[\{2,6-(4,8-didodecylbenzo[1,2b:4,5-b’]dithiophene) $\}$-alt-\{5,5-(2,5-bis(2-butyloctyl)-3,6-dithiophen-2-yl-

2,5dihydropyrrolo[3,4-c] 57pyrrole-1,4-dione)\}] (P(TBT-DPP)) [37] with ICBA. The P(TBT-DPP):ICBA nanoparticles were synthesized in aqueous media following the miniemulsion technique illustrated in Figure 1a. The aqueous nanoparticle (NP) inks were printed by doctor blade coating in air [38] onto PEN/PEDOT:PSS substrates as depicted in Figure 1b and a schematic representation of the device structure is shown in Figure 1c. Conventional bulk heterojunction (BHJ) devices were also deposited by blade coating and used as control devices. Our model based on $[39,40]$ can be applied to fit the dark $J-V$ curves of both conventional $\mathrm{BHJ}$ and nanoparticulate devices. Our model assumes that the dark $J-V$ curves can be obtained using the equivalent circuit illustrated in Figure 1e. The model is composed of a nonlinear space-charge limited series resistance $(R)$, that depends on $J$, connected to a diode (D) in parallel to a shunt resistance $\left(R_{s h}\right)[39,40]$. By means of this 
Space-Charge Limited - Diode (SCL-D) model, relevant parameters such as effective mobility $\left(\mu_{e f f}\right)$ and the diode saturation current $\left(J_{o}\right)$ are quantified and related to the photovoltaic response of the devices.

\section{Experimental Section}

Synthesis and characterization of the nanoparticle inks: dispersions were prepared using P(TBT-DPP) provided by Polyera and ICBA (purchased from Sigma Aldrich). Chloroform solutions of $\mathrm{P}(\mathrm{TBT}-\mathrm{DPP})$ and ICBA $(40 \mathrm{mg} / \mathrm{mL})$ in three donor:acceptor weight ratios (DAWR) (1:1, 3:7 and 1:3) were added to a $5 \mathrm{mg} / \mathrm{mL}$ aqueous sodium dodecyl sulfate (SDS) solution. Preemulsification is achieved by stirring the resulting solution at $1000 \mathrm{rpm}$ during 1 h. Subsequently the mixture was sonicated using a Branson 450 digital sonifier for $2 \mathrm{~min}$ at $60 \%$ amplitude with a microtip (radius $6.5 \mathrm{~mm}$ ) immersed in the emulsion to form the dispersion. Then the samples were heated while stirring for $30 \mathrm{~min}$ at $65^{\circ} \mathrm{C}$ to evaporate the chloroform forming a stable aqueous dispersion. In order to concentrate and eliminate the excess surfactant, dialysis of the nanoparticle dispersion was performed using ultra centrifuge dialysis tubes with $10 \mathrm{kDa}$ molecular weight cutoff (purchased from Millipore). The dialysis procedure was repeated until the surface tension of the filtrated water reached about 38 $\mathrm{mN} / \mathrm{m}$. Dynamic light scattering (Zetasizer Nano-ZS, Malvern Instruments) was used to measure the size distribution of the nanoparticles in the aqueous dispersion. The nanoparticle composition and average particle size measured by Dynamic Light Scattering are summarized in Table 1. The nanoparticle size strongly depends on the initial ratio of surfactant, polymer, fullerene, organic solvent and water. Therefore the synthesis parameters can be tuned in order to control the final particle size. For a given blend ratio, higher amount of blend material leads to larger particle size [41] whereas the increase in the surfactant amount reduces the particle diameter [29]. In this work, the total blend concentration was kept constant at $40 \mathrm{mg} / \mathrm{mL}$ and 
it is shown that the average diameter increases with the amount of ICBA in the blend. The molecular weight of the polymer is $27 \mathrm{kDa}$ [37]. Since the monomer molecular weight of the $\mathrm{P}(\mathrm{TBT}-\mathrm{DPP})$ is approximately $1.12 \mathrm{kDa}$, the weight-average degree of polymerization $\left(n_{w}\right)$ is 24 . The molecular weight of ICBA, the acceptor, is $952.96 \mathrm{Da}$ [42]. Based on the molecular weight values for donor and acceptor materials we can calculate the ratio $(\eta)$ of ICBA molecules per polymer chain for each nanoparticle blend composition. The average density of ICBA molecules per monomer of the polymer inside the nanoparticle $(\rho)$ is then given by $\rho=\eta / V$, where $V$ is the average volume of the nanoparticle (assuming a spherical structure with the diameter given by the DLS measurements). As shown in Table 1, the nanoparticle diameter (and its volume) increase as $\eta$ increases (higher acceptor concentration). However, the density of ICBA per monomer $(\rho)$ reaches a maximum for the 3:7 samples. Optimized nanoparticles inks were prepared with the addition of $20 \%$ of ethanol by volume to the NP dispersion in the DAWR of 3:7 after the dialysis procedure.

Solar cells fabrication and characterization: a double layer of different poly(ethylene dioxythiophene) doped with poly(styrenesulfonic acid) (PEDOT:PSS) compositions is used instead of ITO as the transparent electrode. The first layer of $200 \mathrm{~nm}$ thick provides higher conductivity using Sigma Aldrich 739316-25G which has work function of $5.15 \mathrm{eV}$. This layer was deposited onto pre-cleaned polyethylenenaphthalate (PEN) (DuPont PQA1) substrates using a height-adjustable doctor blade (Zehntner ZUA 2000.60) set up in ambient conditions with a linear servo (Servo City). The blade distance from the substrate was set to be $350 \mu \mathrm{m}$. The PEDOT:PSS film was dried in a hot plate at $120{ }^{\circ} \mathrm{C}$ for 25 minutes. Subsequently the second PEDOT:PSS layer (Clevios $^{\mathrm{TM}}$ AI 4083) was deposited to modify the electrode work function to $5.30 \mathrm{eV}$. The second layer is $100 \mathrm{~nm}$ thick and after deposition the film is dried at $120{ }^{\circ} \mathrm{C}$ for 25 minutes. The dispersions of the P(TBT-DPP):ICBA nanoparticles were doctor blade coated in air onto the PEN/PEDOT:PSS substrates and 
annealed at $150{ }^{\circ} \mathrm{C}$ for 20 minutes. Nanoparticle film thicknesses ranged from 100 to $150 \mathrm{~nm}$. The devices were completed with the deposition of $\mathrm{C}_{60}(40 \mathrm{~nm})$ and $\mathrm{Al}(100 \mathrm{~nm})$ layers thermally evaporated through a shadow mask at pressure of $5 \times 10^{-6}$ mbar. The devices active area was found to be $4 \mathrm{~mm}^{2}$. Conventional bulk heterojunction (BHJ) made from chloroform solutions with the same blend ratios were blade coated onto PEN/PEDOT:PSS substrates in the exact same conditions as the nanoparticles (NP) devices and used as control devices in our studies. For the optimized NP devices, the PEN substrates were exposed to (heptadecafluoro1,1,2,2-tetrahydrodecyl)trichlorosilane (FDTS, Gelest SIH5841.0) for 15 minutes under light vacuum (0.1-1 Torr) [38]. A mask defining the area where the PEDOT:PSS and NP layers will be coated is pressed flush against the substrates then oxygen plasma-treated for 15 seconds at $50 \%$ power. The ethanol modified dispersion of the P(TBT-DPP):ICBA (3:7) nanoparticles were doctor blade coated in air onto the PEN/PEDOT:PSS substrates and the devices were completed with the $\mathrm{C}_{60}(40 \mathrm{~nm})$ and $\mathrm{Al}(100 \mathrm{~nm})$ deposition. Thickness measurements were performed with a Dektak 150 profilometer (Veeco Instruments) and film morphology was investigated using an Asylum MFP-3D Atomic Force Microscope operating in dynamic mode. Photovoltaic characterization was performed with a Keithley picoammeter with power supply. The solar illumination condition was simulated with air mass (AM 1.5) filter and power illumination of $100 \mathrm{~mW} / \mathrm{cm}^{2}$ from a Xenon lamp.

\section{Results and Discussion}

From Figure 1(e), the current of the system is given by $J=J_{s h}+J_{D}$ where $J_{s h}$ is the shunt current density and $J_{D}$ is the diode current density given by the expressions $J_{s h}=\left(V-V_{s c}\right) /\left(R_{s h} A\right)$ and $J_{D}=J_{0}\left(\exp \left[q\left(V-V_{s c}\right) /(k T)\right]-1\right)$, respectively. $A$ is the device active area, $J_{0}$ is the diode saturation current and $V_{s c}$ is the potential drop across a space 
charge limited series resistance $(R)$, given by $V_{S C}=1 / 3 \sqrt{8 J L^{3} /\left(\mu_{e f f} \varepsilon\right)}$ [39], where $L$ is the film thickness and $\varepsilon$ is the dielectric constant of the active layer $\left(\varepsilon \sim 3 \varepsilon_{0}\right)$ [43]. This value of permittivity is commonly assumed for the evaluation of charge carrier mobility of polymeric semiconductors using space-charge limited currents. Therefore the current of the system can be written as:

$$
J=J_{s h}+J_{0}\left(\exp \left[q\left(V-V_{s c}\right) /(k T)\right]-1\right)
$$

The system theoretical dark $J-V$ characteristics can be obtained by solving Equation 1 for a given $J$, where $J_{0}$ and $R_{s h}$ are fitting parameters. From the Mott-Gurney law, $R_{s h}$ this is given by

$$
R_{s h}=8 L^{3} / 9 \varepsilon \mu_{e f f}^{\text {low }} A\left(V-V_{s c}\right)
$$

where $L$ is the sample thickness and $\mu_{e f f}^{\text {low }}$ is the fitting parameter that represents the effective mobility at low $V$.

Applying the SCL-D model to the dark experimental $J$ - $V$ curves gives the charge carriers effective mobility $\left(\mu_{e f f}\right)$ which is also a fitting parameter that determines the space-charge limited (SCL) current at high voltages. The shunt resistance, $R_{s h}$, controls the ohmic behavior at low voltages and $J_{0}$ is given by the steep increase in the current between the ohmic and the SCL regimes [39]. Both, $J_{0}$ and $\mu_{\text {eff }}$ depend on the intrinsic morphology of the photoactive layer and can be directly related to the photovoltaic response of the device. For instance, small $J_{0}$ is associated with higher open circuit voltages by the expression $V_{o c}^{\text {calc }}=(k T / e) \ln \left(J_{s c} / J_{0}\right)$ [44]. Moreover the diode current can be written as [40]

$$
J_{0}=J_{m a t} \exp \left(-E_{D A} / 2 k T\right)
$$

where $E_{D A}$ is the effective energy barrier at the donor/acceptor interface and $J_{\text {mat }}$ is an independent factor determining the carrier recombination rate [40]. $J_{\text {mat }}$ quantifies the inter- 
molecular overlap of the donor and acceptor molecules and the effective area of the donor/acceptor interface. By the same token, $\mu_{e f f}$ is also strongly affected by the morphology of the film at the molecular level. Large domains of donor (acceptor) aggregates create large barriers for hole (electron) transport. The increased volume of those phases tends then to decrease the number of percolation paths that link the dissociation centers to the metallic contacts. As a consequence, large domains of polymer (fullerene) would tend to block the electron (hole) transport toward the collecting electrodes. This effect increases the chances of recombination during free carrier drift that follows exciton dissociation. A higher rate of recombination decreases $\mu_{e f f}$ which results in lower short circuit currents. The film morphologies for compositions of 3:7 (DAWR) for chloroform BHJ and aqueous NP devices were accessed using atomic force microscopy (AFM) and the images are displayed in Figure 2a and 2b, respectively and the phase contrast image simultaneously acquired are shown in Figure 2c and 2d. The conventional BHJ film blade coated from chloroform solutions resulted in large domains in the order of $500 \mathrm{~nm}$ of diameter. In contrast, the P(TBTDPP):ICBA nanoparticle film exhibited phase finer segregation on the order of $100 \mathrm{~nm}$, which is consistent with the DLS measurement for the aqueous dispersion. These images confirm that blend phase segregation fixed during the nanoparticle synthesis is maintained during film deposition and solvent drying. Figure 2e and $2 \mathbf{f}$ shows that there is a good agreement between the model proposed here and the experimental data obtained for both types of morphology. In Table 2 we report the values of $\mu_{e f f}, J_{0}$ and $R_{s h}$ obtained from the model at $\mathrm{V}=0.1 \mathrm{~V}$. As displayed in Table 2, $\mu_{\text {eff }}$ and $J_{0}$ increase for the devices made with higher ICBA density nanoparticle solutions. The larger domains of donor (acceptor) shown in the BHJ film produce higher fluctuations in the local density of ICBA molecules. Those fluctuations mask the dependence of $\mu_{\text {eff }}$ and $J_{0}$ on the bulk density of ICBA that is only apparent in the NP devices where the mixing of the acceptor and donor materials is finer and 
more evenly distributed throughout the film. The values in Table 2 clearly show that the NP devices always give higher $\mu_{\text {eff }}$ and $J_{0}$ when compared to the respective BHJ cells for the same DAWR.

The $J-V$ curves under illumination for conventional BHJ and NP devices in the blend DAWR of 1:1, 3:7 and 1:3 are shown in Figure 3 and all the photovoltaic parameters obtained from these curves are summarized in Table 3.

It was observed in similar polymer/acceptor nanoparticulate photovoltaic devices that NP materials show evidence of a higher inter-chain order compared to the BHJ films [32]. This order tends to increase the effective mobility for the NP devices, increasing $J_{\text {mat }}$ given in Equation 3 which enhances $J_{0}$. In contrast, the lower level of control over the nanoscale morphology in BHJ devices would reduce the effective donor/acceptor heterojunction area, leading to a lower $J_{m a t}$. As a consequence, the NP devices have higher $J_{0}$ when compared to the BHJ devices for the same DAWR. Higher $J_{0}$ translates into lower values of $V_{o c}$ [44]. The NP devices generate lower open circuit voltages under illumination $\left(100 \mathrm{~mW} \mathrm{~cm}{ }^{-2}\right)$ when compared to the respective BHJ devices as it is shown in Table 2. This behavior was also reported when other NP systems were compared to the corresponding BHJ $[32,36]$. The higher density $\rho$ of ICBA molecules per monomer of polymer in the NP sample may increase the electronic coupling between donor and acceptor and the effective area of the resulting heterojunction enhancing $J_{m a t}$. Additionally $J_{0}$ is maximum for the NP sample with the 3:7 DAWR (see Table 2). Consequently it is not surprising that the 3:7 device showed the lower $V_{o c}$ among all tested solar cells (see Table 2). In fact using the relation $V_{o c}^{\text {calc }}=(k T / e) \ln \left(J_{s c} / J_{0}\right)$, the calculated values of the open circuit voltage match the measured $V_{o c}$ values closely except for the BHJ device with DAWR of $1: 1$. The $J-V$ curve of the BHJ 1:1 device does not describe an ohmic behavior at very low applied voltages. Since our model assumes only a transport-limited electrical conduction, the fit of this theory to BHJ 1:1 
experimental data overestimates the dark current $\left(J_{0}\right)$ at low voltages. As a consequence, the calculated $V_{o c}$ underestimate the experimental $V_{o c}$.

A core-shell structure formed of an acceptor rich core surrounded by a polymer-rich shell was previously observed in other nanoparticulate donor/acceptor films [32,37]. Since in those structures the acceptor is reasonably dispersed inside the polymeric shell, the transport would be essentially limited by the hopping of the electrons across thin polymeric layers coating the adjacent ICBA molecules. Assuming that the polymer acts as a potential barrier to interacceptor electron hopping, the transport of electrons between adjacent electronic states localized in the acceptor at constant temperature may depend only on the tunneling part of the hopping rate. It is then reasonable to assume that $\ln \mu_{e f f} \propto-d$ [45], where $d$ is the average distance between neighbor ICBA molecules in the NP. Due to spatial considerations and neglecting the volume of the fullerene molecule compared to the volume of the NP's, one can write $\eta(4 \pi / 3)(d / 2)^{3} \approx V$. It follows then that $d \propto \rho^{-1 / 3}$. This suggests that the relation $\ln \mu_{e f f} \propto-\rho^{-1 / 3}$ is valid for the NP structures used in our study. We use this relation and plot in Figure 4 the effective mobilities from Table 2 as a function of the respective values of $\rho$ taken from Table 1. The predicted linear behavior is observed, with the solid line as a fit to the $\mu_{\text {eff }}$ data. This result indicates that the transport in the NP samples are limited by the interacceptor hopping of electrons across the barriers formed by the polymeric coating due to the finer donor/acceptor mix in the NP films.

Following the analysis above, the reasons behind the best photovoltaic performance obtained for the 3:7 NP solar cell are better understood. First the substantial decrease of the series resistance exponentially increases the effective mobility of the 3:7 NP solar cell. Additionally, the higher concentration of donor/acceptor heterojunctions in this sample (higher $\rho$ ) increases the density of photoexcited excitons upon illumination which enhances $J_{s c}$. Both phenomena 
compensate the lower $V_{o c}$ resulting in the highest PCE compared to the conventional BHJ devices we have analyzed.

Given the good performance shown by the devices with DAWR of 3:7, we further optimized the ink formulation to improve wettability and promote better film formation. $20 \%$ of ethanol in volume was added to the initial 3:7 to decrease the surface tension [46] of the nanoparticle aqueous dispersions. The addition of ethanol to the nanoparticle ink reduces the contact angle between ink and substrate, PEN/PEDOT:PSS, from $59^{\circ}$ to $45^{\circ}$ leading to a more homogeneous film coating. Figure 5 displays the $J-V$ curve under illumination of $100 \mathrm{~mW} \mathrm{~cm}^{-}$

${ }^{2}$ for the optimized NP device and the conventional BHJ in the same DAWR and blade coated in the same conditions. The NP device exhibited six fold increase in the $J_{s c}\left(2.12 \mathrm{~mA} \mathrm{~cm}{ }^{-2}\right.$ for BHJ and $12.73 \mathrm{~mA} \mathrm{~cm}^{-2}$ for the NP) enhancing the PCE from $0.44 \%$ to $2.63 \%$. This result is comparable to the highest PCE reported for P3HT:ICBA nanoparticles dispersed in water and spin coated onto ITO/PEDOT:PSS substrates (2.50\%) [35]. As it is shown in Figure 5, despite the decrease in the $V_{o c}, 0.55 \mathrm{~V}$ to $0.44 \mathrm{~V}$, the NP device has shown remarkable improvement in the fill factor (FF): from $37 \%(\mathrm{BHJ})$ to $46 \%(\mathrm{NP})$. This result is consistent with the decrease in the series resistance $\left(R_{s}\right)$ : from $83 \Omega \mathrm{cm}^{2}(\mathrm{BHJ})$ to $11 \Omega \mathrm{cm}^{2}(\mathrm{NP})$. We attribute the improved photovoltaic response found for the NP devices to the nanostructured film morphology.

\section{Conclusions}

We have fully described the transport properties of $\mathrm{P}(\mathrm{TBT}-\mathrm{DPP})$ :ICBA nanoparticles devices applying the SCL-D model to fit the dark $J-V$ curves and demonstrate that the charge transport is improved for the NP when compared to conventional BHJ devices due to the closer contact between donor/acceptor in the nanoparticle structure. We synthesized P(TBT-DPP):ICBA nanoparticles in aqueous dispersion in three donor to acceptor weight ratios and all the NP devices have shown improved performance when compared to the corresponding BHJ blends 
coated using the same laboratory conditions. The NP devices exhibited higher short current density, higher fill factor and lower series resistance. Moreover the effective mobility dependency with the density of ICBA molecules per monomer of the polymer inside the NP indicates that the transport in the NP film is limited by the inter-acceptor hopping of electrons across barriers formed by the polymeric coating due to the finer donor/acceptor mix in the film. The best blend ratio was found to be (3:7) with optimized devices yielding power conversion efficiency of $2.63 \%$. The aqueous nanoparticle ink significantly reduces the use of hazardous solvents in organic electronics. In addition, it allows control of the donor/acceptor morphology at the nanometer scale without compromising reproducibility in large area devices, such as photovoltaics. Our results confirm the viability of applying aqueous inks based on polymer:fullerene nanoparticles for large-area photovoltaics that are compatible with ITO-free flexible substrates and printing techniques.

\section{Acknowledgements}

This work is based upon work supported in part by the National Science Foundation under Cooperative Agreement No. EEC-1160494. Any opinions, findings and conclusions or recommendations expressed in this material are those of the author(s) and do not necessarily reflect the views of the National Science Foundation. The authors would also like to thank Polyera for providing materials and CNPq and CAPES-PDSE (process BEX - 1564129) for partial financial support.

\section{References}

[1] C. J. Brabec, Organic Photovoltaics: technology and market, Sol. Energy Mater. Sol. Cells 83 (2004) 273-292.

[2] F. C. Krebs, Fabrication and processing of polymer solar cells: A review of printing and coating techniques, Sol. Energy Mater. Sol. Cells 93 (2009) 394-412. 
[3] P. Schilinsky, C. Waldauf, C. J. Brabec, Performance analysis of printed bulk heterojunction solar cells, Adv. Funct. Mater. 16 (2006) 1669-1672.

[4] R. Mens, P. Adriaensens, L. Lutsen, A. Swinnen, S. Bertho, B. Ruttens, J. D'Haen, J. Manca, T. Cleij, D. Vanderzande, J. Gelan, NMR study of the nanomorphology in thin films of polymer blends used in organic PV devices: MDMO-PPV/PCBM, J. Pol. Sci. A Pol. Chem. 46 (2008) 138-145.

[5] A. Schneider, N. Traut, M. Hamburger, Analysis and optimization of relevant parameters of blade coating and gravure printing processes for the fabrication of highly efficient organic solar cells, Sol. Energy Mater. Sol. Cells 126 (2014) 149-154.

[6] S. H. Eom, H. Park, S. H. Mujawar, S. C. Yoon, S.-S Kim, S.-I. Na, S.-J. Kang, D. Khim, D. -Y Kim,S.-H. Lee, High efficiency polymer solar cells via sequential inkjet-printing of PEDOT:PSS and P3HT:PCBM inks with additives, Organic Electronics 11 (2010) 15161522.

[7] C. N. Hoth, P. Schilinsky, S. A. Choulis, C. J. Brabec, Printing highly efficient organic solar cells, Nano Lett. 8 (2008) 2806-2813.

[8] D. Kaduwal, H.-F. Schleiermacher, J. Schulz-Gericke, T. Kroyer, B. Zimmermann, U. Würfel, ITO-free organic solar cells with roll-to-roll coated organic functional layers from non-halogenated solvents, Sol. Energy Mater. Sol. Cells 124 (2014) 92-97.

[9] M. Kaltenbrunner, M. S. White, E. D. Głowacki, T. Sekitani, T. Someya, N. S. Sariciftci, S. Bauer, Ultrathin and lightweight organic solar cells with high flexibility, Nat. Commun. 3 (2012) 770 .

[10] R. V. Salvatierra, C. E. Cava, L. S. Roman, A. J. G. Zarbin, ITO-Free and flexible organic photovoltaic device based on high transparent and conductive polyaniline/carbon nanotube thin films, Adv. Funct. Mater. 23 (2013) 1490-1499.

[11] N. A. D. Yamamoto, L. F. Lima, R. E. Perdomo, R. Valaski, V. L. Calil, A. G. Macedo, M. Cremona, L. S. Roman, Modification of PEDOT:PSS anode buffer layer with HFA for flexible polymer solar cells, Chem. Phys. Lett. 572 (2013) 73-77.

[12] S. H. Park, A. Roy, S. Beaupre, S. Cho, N. Coates, J. S. Moon, D. Moses, M. Leclerc, K. Lee, A. J. Heeger, Bulk heterojunction solar cells with internal quantum efficiency approaching 100\%, Nat. Photon. 3 (2009) 297-302.

[13] H. Zhou, L. Yang, A. C. Stuart, S. C. Price, S. Liu, W. You, Development of fluorinated benzothiadiazole as a structural unit for a polymer solar cell of $7 \%$ efficiency, Angew. Chem. Int. 50 (2011) 2995-2998. 
[14] J. You, L. Dou, K. Yoshimura, T. Kato, K. Ohya, T. Moriarty, K. Emery, C.-C. Chen, J. Gao, G. Li, Y. Yang, A polymer tandem solar cell with $10.6 \%$ power conversion efficiency, Nat. Commun. 4 (2013) 1446.

[15] A. C. Arias, J. D. MacKenzie, R. Stevenson, J. J. M. Halls, M. Inbasekaran, E. P. Woo, D. Richards, R. H. Friend, Photovoltaic performance and morphology of polyfluorene blends: a combined microscopic and photovoltaic investigation, Macromolecules 34 (2001) 60056013.

[16] H. Hoppe, N. S. Sariciftci, Morphology of polymer/fullerene bulk heterojunction solar cells, J. Mat. Chem. 16 (2006) 45-61.

[17] S. Walheim, M. Böltau, J. Mlynek, G. Krausch, U. Steiner, Structure Formation via Polymer Demixing in Spin-Cast Films, Macromolecules 30 (1997) 4995-5003.

[18] M. Boltau, S. Walheim, J. Mlynek, G. Krausch, U. Steiner, Surface-induced structure formation of polymer blends on patterned substrates, Nature 391 (1998) 877-879.

[19] H. J. Snaith, A. C. Arias, A. C. Morteani, C. Silva, R. H. Friend, Charge generation kinetics and transport mechanisms in blended polyfluorene photovoltaic devices, Nano Lett. 2 (2002) 1353-1357.

[20] S.-L. Lim, E.-C. Chen, C.-Y Chen, K.-H. Ong, Z.-K. Chen, H.-F. Meng, High performance organic photovoltaic cells with blade-coated active layers, Sol. Energy Mater. Sol. Cells 107 (2012) 292-297.

[21] C. R. McNeill, S. Westenhoff, C. Groves, R. H. Friend, N. C. Greenham, Influence of nanoscale phase separation on the charge generation dynamics and photovoltaic performance of conjugated polymer blends: balancing charge generation and separation, J. Phys. Chem. C 111 (2007) 19153-19160.

[22] S. Nilsson, A. Bernasik, A. Budkowski, E. Moons, Morphology and phase segregation of spin-casted films of polyfluorene/PCBM blends, Macromolecules 40 (2007) 8291-8301.

[23] J. J. M. Halls, A. C. Arias, J. D. MacKenzie, W. Wu, M. Inbasekaran, E. P. Woo, R. H. Friend, Photodiodes based on polyfluorene composites: influence of morphology, Adv. Mater. 12 (2000) 498-502.

[24] G. Li, V. Shrotriya, J. Huang, Y. Yao, T. Moriarty, K. Emery, Y. Yang, High-efficiency solution processable polymer photovoltaic cells by self-organization of polymer blends, Nat. Mater. 4 (2005) 864-868. 
[25] X. Yang, J. Loos, S. C. Veenstra, W. J. H. Verhees, M. M. Wienk, J. M. Kroon, M. A. J. Michels, R. A. J. Janssen, Nanoscale morphology of high-performance polymer solar cells, Nano Lett. 5 (2005) 579-583.

[26] L. H. Nguyen, H. Hoppe, T. Erb, S. Günes, G. Gobsch, N. S. Sariciftci, Effects of annealing on the nanomorphology and performance of poly(alkylthiophene):fullerene bulkheterojunction solar cells, Adv. Funct. Mater. 17 (2007) 1071-1078.

[27] K. Kim, J. Liu, D. L. Carroll, Thermal diffusion processes in bulk heterojunction formation for poly-3-hexylthiophene/C60 single heterojunction photovoltaics, Appl. Phys. Lett. 88 (2006) 181911.

[28] C. V. Hoven, X.-D. Dang, R. C. Coffin, J. Peet, T.-Q. Nguyen, G. C. Bazan, Improved performance of polymer bulk heterojunction solar cells through the reduction of phase separation via solvent additives, Adv. Mater. 22 (2010) E63-E66.

[29] K. Landfester, R. Montenegro, U. Scherf, R. Güntner, U. Asawapirom, S. Patil, D. Neher, T. Kietzke, Semiconducting polymer nanospheres in aqueous dispersion prepared by a miniemulsion process, Adv. Mater. 14 (2002) 651-655.

[30] T. Kietzke, D. Neher, K. Landfester, R. Montenegro, R. Guntner, U. Scherf, Novel approaches to polymer blends based on polymer nanoparticles, Nat. Mater. 2 (2003) 408-412. [31] B. Vaughan, A. Stapleton, B. Xue, E. Sesa, X. Zhou, G. Bryant, W. Belcher, P. Dastoor, Effect of a calcium cathode on water-based nanoparticulate solar cells, Appl. Phys. Lett. 101 (2012) 053901.

[32] S. Ulum, N. Holmes, D. Darwis, K. Burke, A. L. D. Kilcoyne, X. Zhou, W. Belcher, P. Dastoor, Determining the structural motif of P3HT:PCBM nanoparticulate organic photovoltaic devices, Sol. Energy Mater. Sol. Cells 110 (2013) 43-48.

[33] T. T. Larsen-Olsen, B. Andreasen, T. R. Andersen, A. P. L. Böttiger, E. Bundgaard, K. Norrman, J. W. Andreasen, M. Jørgensen, F. C. Krebs, Simultaneous multilayer formation of the polymer solar cell stack using roll-to-roll double slot-die coating from water, Sol. Energy Mater. Sol. Cells 97 (2012) 22-27.

[34] T. R. Andersen, T. T. Larsen-Olsen, B. Andreasen, A. P. L. Böttiger, J. E. Carlé, M. Helgesen, E. Bundgaard, K. Norrman, J. W. Andreasen, M. Jørgensen, F. C. Krebs, Aqueous processing of low-band-gap polymer solar cells using roll-to-roll methods, ACS Nano 5 (2011) 4188-4196.

[35] S. Ulum, N. Holmes, M. Barr, A. L. D. Kilcoyne, B. B Gong, X. Zhou, W. Belcher, P. Dastoor, The role of miscibility in polymer:fullerene nanoparticulate organic photovoltaic devices, Nano Energy 2 (2013) 897-905. 
[36] B. Vaughan, E. L. Williams, N. P. Holmes, P. Sonar, A. Dodabalapur, P. C. Dastoor, W. Belcher, Water-based nanoparticulate solar cells using a diketopyrrolopyrrole donor polymer, Phys. Chem. Chem. Phys. 16 (2014) 2647-2653.

[37] A. Pierre, S. Lu, I. A. Howard, A. Facchetti, A. C. Arias, Empirically based device modeling of bulk heterojunction organic photovoltaics, J. Appl. Phys. 113 (2013) 154506.

[38] A. Pierre, M. Sadeghi, M. M. Payne, A. Facchetti, A. C. Arias, All-printed flexible organic transistors enabled by surface tension-guided blade coating, Adv. Mater. 26 (2014) $5722-5727$.

[39] M. Koehler, N. A. D. Yamamoto, A. G. Macedo, D. Z. Grodniski, L. S. Roman, M. G. E. da Luz, The current-voltage characteristics of polymer/ $\mathrm{C}_{60}$ diodes in the dark: A direct way to assess photovoltaic devices efficiency parameters, Appl. Phys. Lett. 103 (2013) 033304.

[40] M. D. Perez, C. Borek, S. R. Forrest, M. E. Thompson, Molecular and morphological influences on the open circuit voltages of organic photovoltaic devices, J. Am. Chem. Soc. 131 (2009) 9281-9286.

[41] T. Kietzke, D. Neher, M. Kumke, R. Montenegro, K. Landfester, U. Scherf, A nanoparticle approach to control the phase separation in polyfluorene photovoltaic devices, Macromolecules 37 (2004) 4882-4890.

[42] http://www.sigmaaldrich.com/catalog/product/aldrich/753955?lang=en\&region=US

[43] M. Pope, C. E. Swenberg, Electronic Process In Organic Crystals and Polymers, $2^{\text {nd }}$

Edition, Oxford University Press, Oxford (1999).

[44] K. Vandewal, K. Tvingstedt, A. Gadisa, O. Inganas, J. V. Manca, On the origin of the open-circuit voltage of polymer-fullerene solar cells, Nat. Mater. 8 (2009) 904-909.

[45] A. Miller, E. Abrahams, Impurity conduction at low concentrations, Phys. Rev. 120 (1960) 745 .

[46] G. Vazques, E. Alvarez, J. M. Navaza, Surface tension of alcohol water + water from 20 to 50 degree C, J. Chem. Eng. Data 40 (1995) 611-614. 

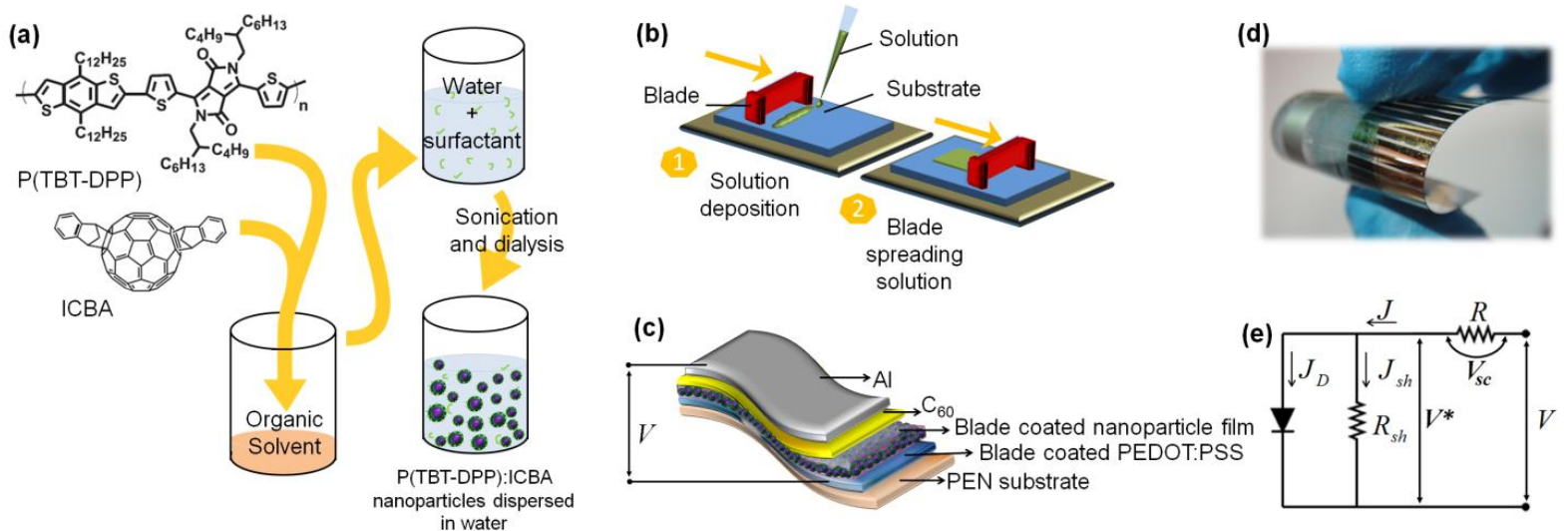

Figure 1. (a) Simplified scheme of the nanoparticle synthesis: organic solvent solution containing P(TBT-DPP) and ICBA is added to an aqueous solution containing surfactant, this mixture is sonicated to form the nanoparticle dispersion and after a dialysis process the nanoparticle ink is ready for priting; (b) scheme describing the doctor blade coating technique; (c) device structure: PEN/PEDOT:PSS/NP P(TBTDPP):ICBA/C $60 / \mathrm{Al}$; (d) device photograph and (e) equivalent circuit used to model the dark $J-V$ response of the devices: $R$ is the series resistance, $R_{s h}$ is the shunt resistance, $V_{\mathrm{sc}}$ is the potential drop across $\mathrm{R}, J_{D}$ is the diode current, $J_{s h}$ is the shunt current and $J$ is the total current of the system. 

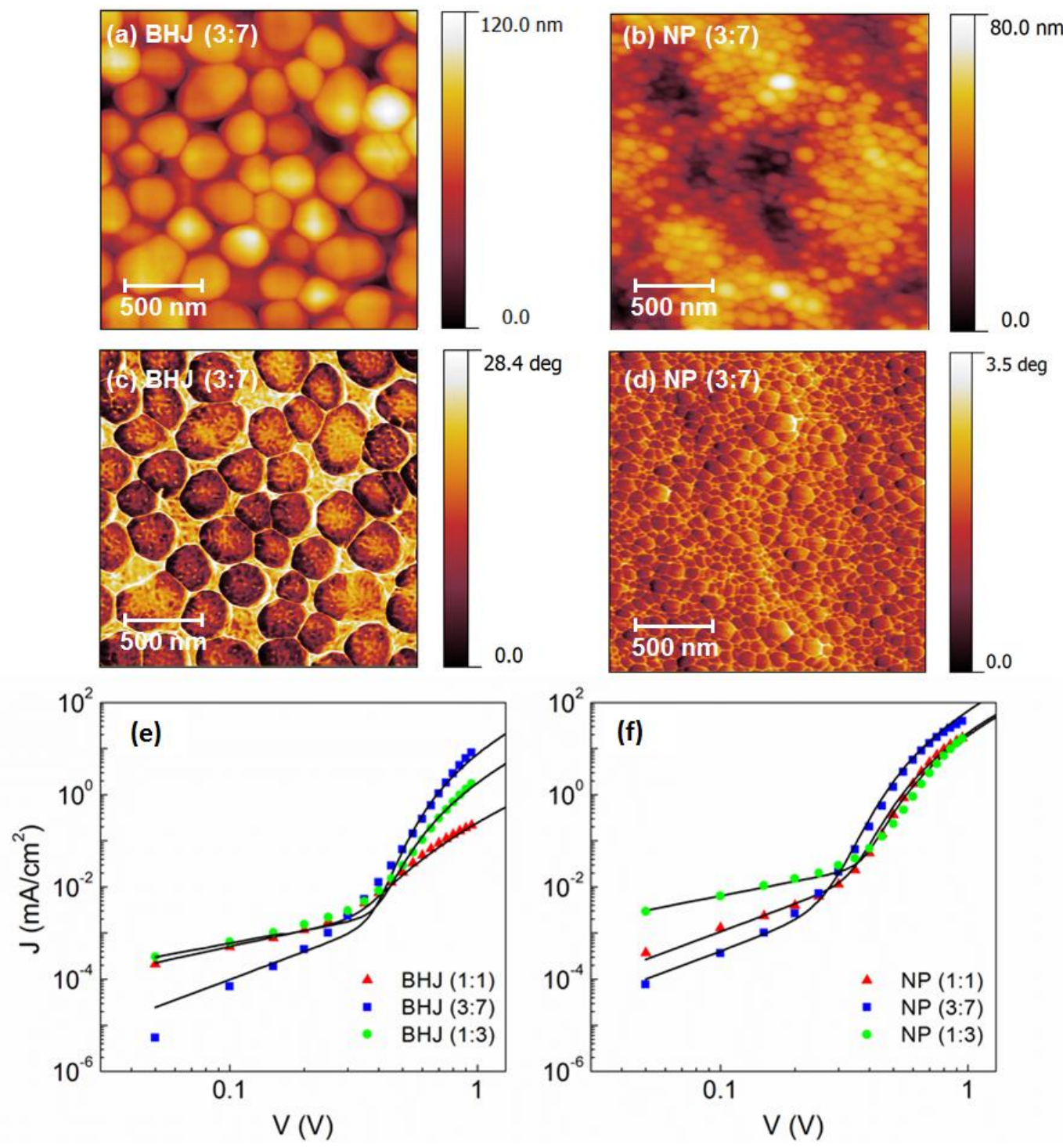

Figure 2. Atomic Force Microscopy (AFM) topography map of (a) conventional P(TBT-DPP):ICBA BHJ and (b) NP films blade coated onto PEN/PEDOT:PSS substrates and phase contrast images simultaneously acquired for (c) conventional P(TBT-DPP):ICBA BHJ and (d) NP films. The scan size is $2 \mu \mathrm{m} \times 2 \mu \mathrm{m} . J-V$ curves in the dark from conventional (e) BHJ and (f) NP devices based on the blend P(TBT-DPP):ICBA in the weight rates: 1:1 (triangle), 3:7 (square) and 1:3 (circles). Solid lines are obtained from the fitting of the experimental curves using the proposed model. 
(a)

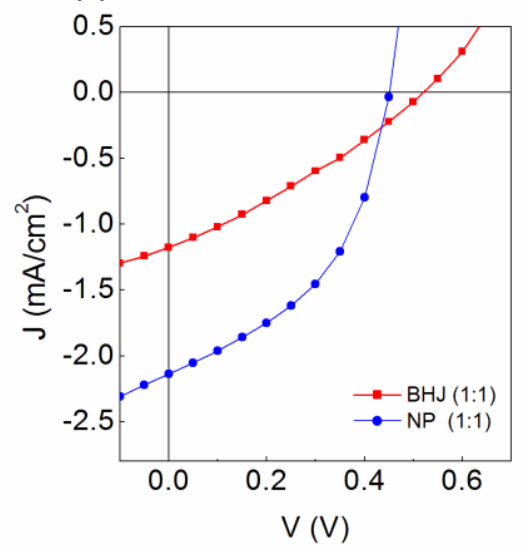

(b)

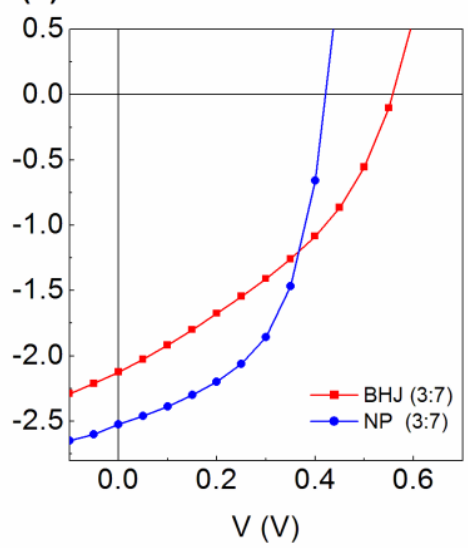

(c)

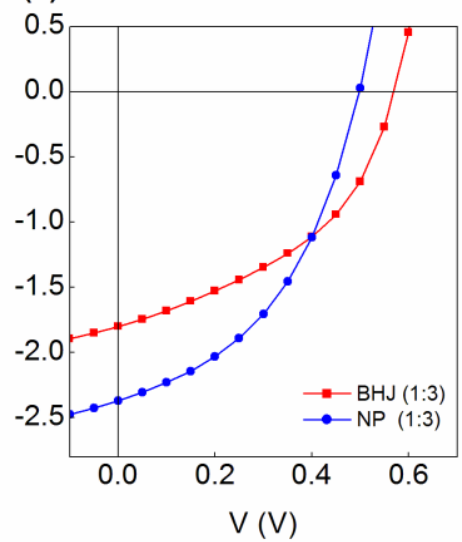

Figure 3. $J-V$ curves under AM 1.5 illumination of $100 \mathrm{~mW} / \mathrm{cm}^{2}$ from conventional BHJ and NP devices based on the blend P(TBT-DPP):ICBA in the weight rates: (a) 1:1, (b) 3:7 and (c) 1:3.

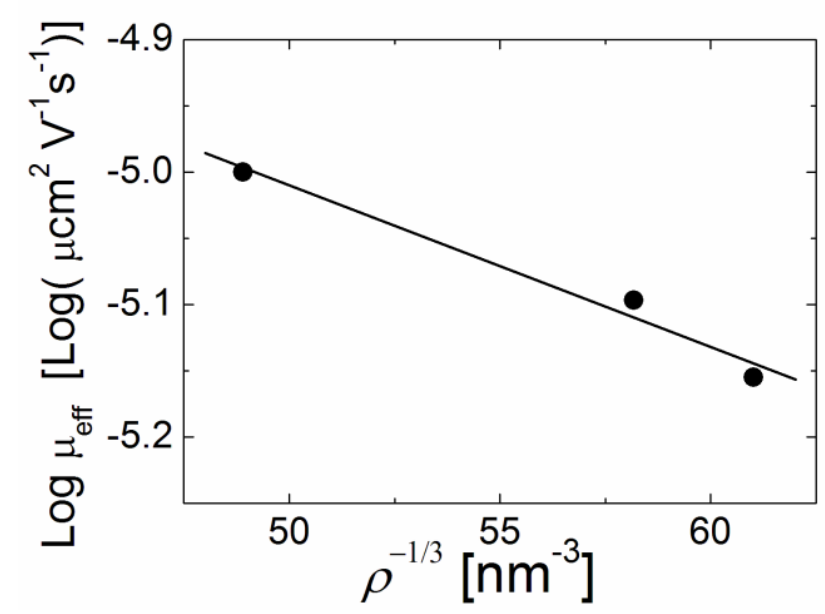

Figure 4. Logarithm of the effective mobility as a function of $\rho^{-1 / 3}$. The solid line is a linear fit to the data. 


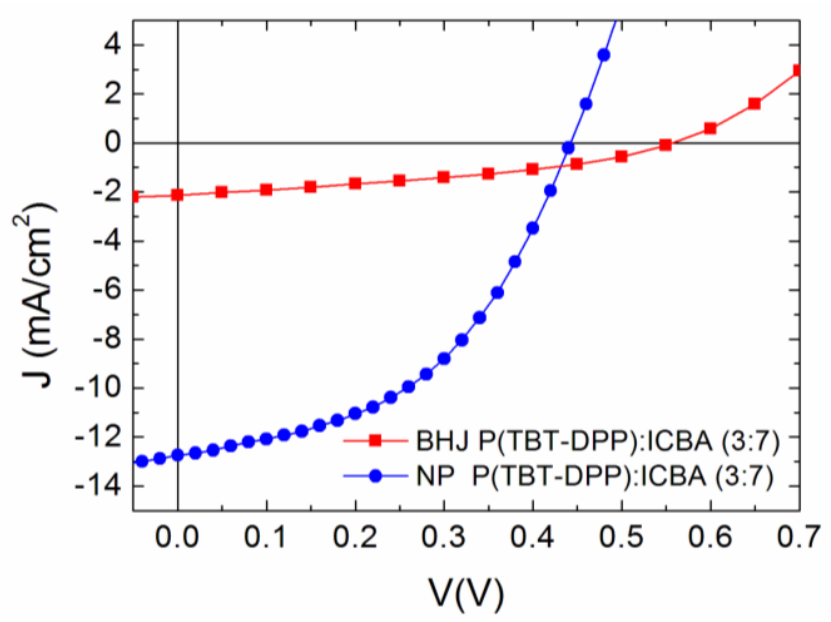

Figure 5. $J-V$ curves under AM 1.5 illumination of $100 \mathrm{~mW} / \mathrm{cm}^{2}$ from conventional $\mathrm{BHJ}$ and optimized NP (addition of $20 \%$ of EtOH) devices based on the blend P(TBT-DPP):ICBA in the weight ratio of 3:7.

Table 1. Composition and properties of the P(TBT-DPP):ICBA nanoparticles.

\begin{tabular}{cccccc}
\hline $\begin{array}{c}\text { Blend weight } \\
\text { ratio }\end{array}$ & $\begin{array}{c}\text { Mass of } \\
\text { P(TBT- } \\
\text { DPP) } \\
{[\mathrm{mg}]}\end{array}$ & $\begin{array}{c}\text { Mass of } \\
\text { ICBA } \\
{[\mathrm{mg}]}\end{array}$ & $\begin{array}{c}\text { Mean } \\
\text { diameter } \\
{[\mathrm{nm}]}\end{array}$ & $\eta$ & $\begin{array}{c}\rho \\
{[\mathrm{nm}]^{-3}}\end{array}$ \\
\hline$(1: 1)$ & 20 & 20 & 80 & 1.18 & $4.40 \times 10^{-6}$ \\
$(3: 7)$ & 12 & 28 & 85 & 2.75 & $8.55 \times 10^{-6}$ \\
$(1: 3)$ & 10 & 30 & 110 & 3.54 & $5.08 \times 10^{-6}$ \\
\hline
\end{tabular}

Table 2. Fitting parameters of the experimental dark $J$ - $V$ curves from Figure 3 taking shunt resistance values given by Eq. (2) at $\mathrm{V}=0.1 \mathrm{~V}$.

\begin{tabular}{cccccc}
\hline $\begin{array}{c}\text { Blend weight } \\
\text { ratio }\end{array}$ & $\boldsymbol{J}_{\boldsymbol{o}}$ & $\begin{array}{c}\mu_{\text {eff }} \\
{\left[\mathrm{cm}^{2} \mathrm{~V}^{-1} \mathrm{~s}^{-1}\right]}\end{array}$ & $\begin{array}{c}\boldsymbol{R}_{\text {sh }} \\
{\left[\Omega . \mathrm{cm}^{2}\right]}\end{array}$ & $\begin{array}{c}V_{o c}^{\text {exp }} \\
{[\mathrm{V}]}\end{array}$ & $\begin{array}{c}V_{o c}^{\text {calc }} \\
{[\mathrm{V}]}\end{array}$ \\
\hline BHJ (1:1) & $3 \times 10^{-8}$ & $6.5 \times 10^{-14}$ & $1.43 \times 10^{5}$ & $0.52 \pm 0.09$ & 0.45 \\
$\mathrm{NP}(1: 1)$ & $4 \times 10^{-8}$ & $7.0 \times 10^{-12}$ & $7.90 \times 10^{5}$ & $0.45 \pm 0.02$ & 0.47 \\
$\mathrm{BHJ}(3: 7)$ & $1 \times 10^{-9}$ & $5.0 \times 10^{-12}$ & $5.66 \times 10^{5}$ & $0.55 \pm 0.01$ & 0.56 \\
$\mathrm{NP}(3: 7)$ & $2 \times 10^{-1}$ & $1.0 \times 10^{-11}$ & $3.34 \times 10^{5}$ & $0.42 \pm 0.01$ & 0.42 \\
$\mathrm{BHJ}(1: 3)$ & $1 \times 10^{-9}$ & $1.0 \times 10^{-12}$ & $1.66 \times 10^{5}$ & $0.57 \pm 0.01$ & 0.55 \\
$\mathrm{NP}(1: 3)$ & $2 \times 10^{-8}$ & $8.0 \times 10^{-12}$ & $1.43 \times 10^{4}$ & $0.49 \pm 0.03$ & 0.48 \\
\hline
\end{tabular}


Table 3. Device characteristics of the conventional BHJ and NP tested under AM 1.5 conditions (from Figure 4).

\begin{tabular}{ccccccc}
\hline $\begin{array}{c}\text { Blend } \\
\text { weight } \\
\text { ratio }\end{array}$ & $\begin{array}{c}\text { Active } \\
\text { layer } \\
\text { thickness } \\
{[\mathrm{nm}]}\end{array}$ & $\begin{array}{c}\boldsymbol{J}_{s c} \\
{\left[\mathrm{~mA} \mathrm{~cm} \mathrm{~cm}^{-2}\right]}\end{array}$ & $\begin{array}{c}\boldsymbol{V}_{\text {oc }} \\
{[\mathrm{V}]}\end{array}$ & $\begin{array}{c}\mathbf{F F} \\
{[\%]}\end{array}$ & $\begin{array}{c}\boldsymbol{R}_{\boldsymbol{s}} \\
{\left[\Omega \mathrm{cm}^{2}\right]}\end{array}$ & $\begin{array}{c}\text { PCE } \\
{[\%]}\end{array}$ \\
\hline $\mathrm{BHJ}(1: 1)$ & $140 \pm 10$ & $1.17 \pm 0.21$ & $0.52 \pm 0.09$ & $30 \pm 6$ & $285 \pm 72$ & $0.18 \pm 0.03$ \\
$\mathrm{NP}(1: 1)$ & $130 \pm 10$ & $2.14 \pm 0.24$ & $0.45 \pm 0.02$ & $45 \pm 6$ & $47 \pm 11$ & $0.44 \pm 0.05$ \\
$\mathrm{BHJ}(3: 7)$ & $120 \pm 8$ & $2.12 \pm 0.08$ & $0.55 \pm 0.01$ & $37 \pm 3$ & $83 \pm 10$ & $0.44 \pm 0.02$ \\
$\mathrm{NP}(3: 7)$ & $110 \pm 15$ & $2.53 \pm 0.13$ & $0.42 \pm 0.01$ & $52 \pm 5$ & $31 \pm 7$ & $0.56 \pm 0.05$ \\
$\mathrm{BHJ}(1: 3)$ & $150 \pm 5$ & $1.80 \pm 0.27$ & $0.57 \pm 0.01$ & $44 \pm 3$ & $71 \pm 17$ & $0.44 \pm 0.06$ \\
$\mathrm{NP}(1: 3)$ & $140 \pm 12$ & $2.37 \pm 0.18$ & $0.49 \pm 0.03$ & $44 \pm 5$ & $64 \pm 13$ & $0.52 \pm 0.08$ \\
$\mathrm{NP}{ }^{\text {a) }}(3: 7)$ & $100 \pm 26$ & $10.49 \pm 2.65$ & $0.43 \pm 0.01$ & $47 \pm 5$ & $12 \pm 3$ & $2.16 \pm 0.50$ \\
$\mathrm{NP}^{\text {b) }}(3: 7)$ & $100 \pm 26$ & 12.73 & 0.44 & 47 & 11 & 2.63 \\
\hline
\end{tabular}

a) Optimized NP devices with the addition of $20 \%$ of ethanol in the NP ink, b) best performing device (NP $3: 7$ with $20 \%$ EtOH), values taken from Figure 5. 